early as the year 1847, and continued, with little variation, for tour years; for-

\begin{tabular}{|c|c|c|c|c|}
\hline In 1846 & & & ed 3 & eaths \\
\hline " 1847 & , & و & 15 & " \\
\hline , 1848 & " & و & 20 & ", \\
\hline " 1849 & ” & ? & 15 & " \\
\hline$\Rightarrow 1850$ & " & " & 19 & " \\
\hline "1851 & 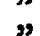 & , & 19 & " \\
\hline
\end{tabular}

A very rapid increase occurred during the early part of this year. On the 10th of January, there were no less than four deaths from carbuncle, all the victims being males bordering upon seventy years of age. The circumstance of four deaths from carbuncle occurring in one day, is remarked upon by the Registrar-General as an unusual occurrence; and it is probable that no such event has happened in London since the last visitation of the plague.

From these records, it would appear that the epidemic has existed in London for four years at the least, and that it arrived at its greatest severity in January, 1852. The next question is, have we seen the worst of it? The following table will help us to a conjecture on this point:-

Single months, 1852.

In January there were registered 8 deaths,

$\begin{array}{lllll}\text { "February } & \text { " } & \text { " } & 4 & \text { " } \\ \text { March } & \text { " } & \text { ", } & 3 & \text { " } \\ \text { April } & \text { May } & \text { " } & 0 & \text { " } \\ \text { "June } & \text { " } & \text { " } & 2 & \text { ", }\end{array}$

If, therefore, the course of this disease is to be expected to follow that of other epidemics, it may be believed to be on the decline in the metropolis; but when we reflect that it has already existed four years or more, we shall not be disposed to arrive at any hasty conclusion, founded on the history of only as many months.

The pathology of this epidemic appears to be involved in some degree of obscurity, but its whole history points to one striking peculiarity-viz., a tendency to the formation and discharge of PURULENT MATTER; this tendency being confined to the SURFACE of the body. And this is curiously confirmed by the fact, that, while the deaths from "abscess" appear to have diminished in number during the prevalence of the epidemic, that term being applied generally to lumbar, or other deepseated collections of matter, the deaths from "phlegmon" appear to have more than trebled their usual number during the last few years-this term being employed to denote superficial inflammation generally, tending to suppuration.

From Philadelphia, accounts have reached us of the great prevalence of superficial abscesses and whitlows, as well as carbuncles and boils. And as regards the pustule or small boil, another very remarkable circumstance should not be overlooked. The small-pox is a febrile disease, consisting of an eruption of pustules, and often terminating in very troublesome and unmanageable boils and superficial abscesses, as sequelæe of the disease. Now, it cannot be viewed as an indifferent question-Has the small-pox prevailed with any unusual degree of severity during the existence of the furunculoid epidemic? To this question the Reports of the RegistrarGeneral return a satisfactory reply. During the last twelve years the average annual deaths from small-pox in the metropolitan districts are recorded as follows:-

\begin{tabular}{|c|c|c|}
\hline & & \\
\hline $\begin{array}{l}0,41,42,43, \text { average } \\
4,45,46,47\end{array}$ & & 76 \\
\hline $\begin{array}{l}1844,45,46,47, \quad " \quad " \\
1848,49,50,51, \quad "\end{array}$ & $\cdot$ & 981 \\
\hline Last quarter of 1851,33 & 9 deaths; & $\begin{array}{r}924 \\
1356\end{array}$ \\
\hline First quarter of 1852,338 & 8 deaths; & 1552 \\
\hline Second quarter of 1852 , & 472 deaths; rate & 1888 \\
\hline
\end{tabular}

From this table it appears that there had been no remarkable increase of small-pox until within the nine months terminating at Midsummer, 1852 , during which period it steadily advanced until it doubled its average number of victims. Nor can it be doubted that the number of cases occurring after vaccination has recently been very much on the increase. Vaccinated persons, previously exposed with impunity to variolous contagion, have recently taken the disease; and whatever bo the cause, there evidently exists, among all classes of society, a most remarkable susceptibility to the variolous poison.

Here then are two distinct epidemics running a race with each other, having only one feature in common-viz., a disposition to superficial pustulation. Is there any instruction to be gained by the study of this curious analogy? Does an epidemic tendency to suppuration predispose to the contagion of a specific disease? In the hospital at Vienna, Dr. Mauthner reports that cases of variola and eczema impetiginodes were often observed during last winter. The latter disease had several points of resemblance to variola. Vesicles were formed, filled with a turbid purulent fluid; these were developed into pustules, and finally desquamated. In several cases rigors occurred on the ninth day of the vesicles. IIere is another link in the chain. The vesicles of eczema do not usually degenerate into pustules, nor are they followed by critical rigors; and there must have been some cause at work to bring a multitude of these cases together in one hospital at one time. Another remarkable circumstance is mentioned by Dr. Mauthner:-Where a marked predisposition to scrofula existed, the disease promoted its development; but it freed the body from local scrofulous affections already existing. In accordance with this, is the general experience as to the health of patients subsequently to an attack of the furuncular or anthracic form of the disease. It has almost invariably improved. There is no "wise saw" more familiar than that "boils are healthy"-i. e., they have a healthy tendency; and it is certainly confirmed by the history of the present epidemic, which may be said to have arrested attention, not so much from its immediate morbitic influence on the vital economy, as from the local disturbance created by the process of elimination. The improvement in the condition of the health of those patients in whom this process has terminated favourably, is not less remarkable.

It is to be regretted that so little is known of the design and uses of the secretion of purulent matter. A general impression exists that its absorption is injurious to the economy, and that its discharge is eliminative and salutary. The opinion is also gaining ground, that under certain morbid conditions of the blood, a vicarious discharge of pus from the kidneys is one of the modes by which nature seelss relief. Dr. Golding Bird assures us, that " many pathologists, especially in Germany, have declared their belief in the frequent occurrence of this phenomenon, and cases have been recorded of empyema dis. appearing contemporaneously with the discharge of purulent urine."* We must, for the present, remain in ignorance of the precise condition of the blood in which the formation and discharge of purulent matter are useful to the system. But the history of this epidemic, taken in connexion with the prevalence of small-pox and the pustular form of eczema, may possibly throw some important light upon future esearches. Alfred-place, Bedford-square, August, 1852.

\section{CASE OF DEATH FROM THE FORMATION OF A FIBRINOUS CONCRETION IN THE HEART.}

\section{By WALTER GaRSTaNG, M.D., M.R.C.S., L.A.C., \&c.}

ON the 10 th of February last I was requested to visit Mr. a gentleman sixty-four years of age, who had been seized with erysipelas of the head and face. He was of a gouty diathesis, and had lived at all times freely. On some occasions he had shown signs of congestion of the liver, and even of ascites, but these attacks had alwass been removed by the usual treatment. On the present occasion these last-named symptoms were combined with the erysipelatous disorder. The erysipelas had given rise to much swelling of the head and face; the pulse was at 94 , and moderately full; the tongue covered with a thick fur; bowels costive; motions deficient in bile; urine small in quantity, and of a high colour. I ordered, in the first instance, an aperient of calomel and colocynth; afterwards a mixture containing antimony and nitrate of potass every three hours; a cold lotion to be applied to the inflamed parts. On the following day the urine deposited lithates, the bowels acted well, the tongue was clean, the pulse at 90 , and the inflammation abating. Favourable symptoms continued for a fortnight, and the patient became able to sit up for several hours during the day. His diet was improved, and he was allowed a small quantity of sherry at dinner. During the course of three weeks, from this point, there was not much change; the appetite was good, the digestive functions were performed well, the inflammation was gone, but the system did not seem to regain strength, and the heart's action was very feeble, the radial pulse being at 80 , and weak. At the time now named (five weeks from the first attack) the patient took a slight cold, and a mild repetition of the erysipelas and of the hepatic derangement appeared. These symptoms, however, were checked as speedily as before, the appetite returned, and digestion seemed to be easily accomplished, and yet, with all these favourable 
appearances, his strength failed; the action of the heart and the respiratory movements gradually grew feebler, and at length, without any sign of pulmonary, cerebral, or abdominal disease, these asthenic symptoms terminated slowly in death, just eleven weeks after the first commencement of the erysipelatous attack.

Post-mortem Examination. - With the exception of a slight enlargement of the liver, we could find no organ exhibiting structural change. The lungs were perfectly bealthy. Upon opening the heart, however, we discovered what, in my opinion, fully accounts for the gradual dissolution: a fibrinous mass filled both its right cavities, and sent up large and long branches into the pulmonary artery and its ramifications. 'The concretion was frm and white, and had an attachment to the walls of the heart.

Remarks. - I have but few remarks to make on this interesting case, and I should probably never have thought of publishing it at all had not my attention been forcibly drawn during the last few months to certain observations which have been made before the Medical Society of London by Mr. B. W. Richardson, "On the Fibrinous Element of the Blood," and which have been reported in the columns of THE LANCET. I find that in a paper read by Mr. Richardson in November last, he thus observes: "Lastly, in cases of asthenia, where fibrinous concretions exist in the heart, the very cessation of the act of life may be owing to their presence and gradual increase, the central organ of the circulation becoming literally choked by them," (THE LANCET, 1851, vol. ii. p. 515 .)

In January, again, the same author briefly alluded to this subject, and produced a patbological specimen, which strongly supported his views, (The LANCET, 1852, vol. i. p. 121 ;) and lastly, in the month of March, on exhibiting another heart in which a fibrinous clot was found, he gave more enlarged riews on the matter, and threw out the idea, that during those diseases which are known to be attended with an abnornal quantity of fibrine in the blood, it may be that some of the overplus of fibrine is deposited on the elevated structures of the moving heart; and he concluded by saying, that " in all inflammatory cases marked by great superfibrination of the blood, and which end by what is called sinking, it would be interesting to learn how far similar concretions in the heart may be concerned in bringing about the sinking state," (THE LANCET, 1852, vol. i. p. 355.)

Now, without wishing to mention the many theoretical points which Mr. Richardson and other physiologists enter into, with reference to the formation of fibrine, \&c., I cannot but observe that the case which I have related above affords striking testimony as to the correctness of the opinions from which $I$ have just quoted. Mr patient had suffered from erysipelas, a disease in which the blood is always superfibrinized; he sank in the most gradual manner, and the autopsy revealed no cause for the sinking, except (what was surely sufficient) a large fibrinous concretion in the heart. Of course, the narration of a single case does not go far to establish any new opinion, but perhaps it may excite others to turn their attention to the same surject. I have been puzzled over and over again at seeing patients gradually sink into death after some slight disorder, with no evident disease that could account for such a serious result. Now, if any ex planation so simple as that given by Mr. Richardson should prove, after further research, to account for some of these occurrences, a great step in the practice of medicine will certainly have been made. I shall look forward for further investigations on this subject with exceeding interest.

Dobcross, near Manchester, August, 1852.

\section{CASE OF RUPTURE OF THE PERITONEAL COAT OF THE UTERUS. \\ BX RICHARD LEE, B.A., Surgeon.}

Mrs. C-_, aged forty-five, wife of an agricultural labourer, having been in good health and occupied with her usual household duties on the previous evening, was taken in labour with her tenth child about four o'clock on the morning of the 18th of April. The pains were confined to the back, and very feeble, ceasing altogether in less than an hour.

At nine o'clock, a medical attendant, one Mr. Smith, arrived, and having made a vaginal examination, gave it as his opinion that "all was going on well, but the labour would not be over for some time;" when, ordering gin-and-water to be administered, he left. Three doses of the ordered stimulant were administered, and at a quarter before one the patient was suddenly discovered to have lost all power, either of motion or speech. Mr. Smith was again sent for. He arrived at one o'clock, but only in time to see her expire. No efforts were made to preserve the clith.

A coroner's inquest was appointed, and I received an order to examine the body of the deceased, whick I did, assisted by Mr. Cogan. The external appearance was unusually healtby, presenting no signs of tmaciation or injury. Of her previous labours we could learn $t$ nt little, except that they had been unaccompanied by anything unusual. The muscles of the abdomen were of natural development; the lungs remarkably bealthy, no adhesions; heart small and rather pale, cavities empty; abdominal viscera healthy, but in the cavity of the abdomen we discovered about three pints of dark liquid blood; the uterus appeared healthy, and of natural development; the os dilated to the size of a sixpence, not stained with blood at any point. Raising the uterus, we discovered, on the posterior surface, about the centre, a rupture in the peritonæal coat, extending transversely between ten and eleren inches, the margins being, in the centre, two and a half inches apart. Above, and parallel with this, was a second rent seven inches long and three-quarters of an inch wide. They both crossed a large vein the size of a goosequill from which the principal hæmorrhage occurred. On opening the uterus anteriorly down the middle line, we found the whole internal surface, on that side, covered by an unusually large placenta. The membranes had not been ruptured, but contained only a small amount of liquor amnii; also a healthy male foetus at the full period of gestation, head presenting.

This case is interesting in various points, among which by no means the least is its comparative rarity, the injury being confined exclusively to the peritonæum. The os uteri was thin and yielding, the liquor amnii present, though not in large amount, and no perceptible contraction had taken place for seven hours and a half before the accident occurred; facts which, taken together, would strengthen the opinion that the walls of the uterus become expanded just previous to a contraction, on which hypothesis an accident of this kind would easily be explained; whereas I do not think anything very satisfactory can be attained if we are to regard it as the result of contraction alone.

A second question arises, would it not have been possible to save the child? I leave this to be answered by the profession, but for my own part consider that no means should be omitted by a medical man to save the life even of an unborn fœetus.

Wheatley, August, 1852.

\section{ON A CASE OF PHLEGMASIA DOLENS OF THE UPPER EXTREMITY, OCCURRING AFTER PARTURITION.}

\section{Br J. M. WINN, M.D.}

ON the 13th of April last, I was called in to see a Mrs. $\mathrm{G}-$, about forty years of age, residing near the Mile-end road, and who had been delivered of her ninth child thirteen days before I saw her. I found her in a sinking state. The countenance was extremely anxious; the abdomen tympanitic and distended to an enormous extent; the pulse small and rapid; and the mind confused. The peculiar and very remarkable symptom, however, was a pale, hard, and extremely painful tumefaction of the whole of the right arm, extending from the shoulder, in an even and diffused manner, to the extremities of the fingers. The lower extremities of the body were not affected.

Mr. Hall, of the Mile-end-road, who was in attendance on the case, informed me that his patient had been delivered by a midwife, that she had suffered from occasional rigors, and also from pain (without swelling) of the left shoulder, as if the disease were about to affect both upper extremities.

We ordered milk and brandy, but it was evident that nothing could save her, and she died early on the following morning.

There can be no doubt that the above case was a most unusual form of phlegmasia dolens. I cannot, indeed, fiud on record a single instance of phlegmasia dolens of an upper extremity occurring after parturition. Dr. Ramsbotharn, in the last edition of his work on Midwifery, alludes to phlegmasia dolens of the arm as an occasional sequela of carcinoma mammæ; and Drs. Stokes and Graves mention similar cases as complications of typhus, but in no instance as occurring after parturition.

The cases which approximate most closely to the one I have instanced are those (Nos. 1 and 2) published by Mr. Coulson, in his interesting "Observations on Affections of the Joints in the Puerperal State;" but in these cases the disease and pain were principally referred to the neighbourhood of the joints.

I am sorry to add, that every effort to obtain a post-mortem examination was made in vain.

Finsbury-square, August 1852. 